\title{
Modeling the assessment of the pre-school children's motor and linguistic skills
}

\author{
Ardian Shingjergji ${ }^{1, *}$, Besa Shingjergji ${ }^{2, * *}$ \\ ${ }^{1}$ Faculty of Education Sciences, Lagjia "Visarion Xhuvani" University of Elbasan, \\ rruga "7 Marsi", nr. 7693, Elbasan 3001, Albania \\ ${ }^{2}$ Faculty of Human Sciences, Lagjia "Visarion Xhuvani" University of Elbasan, \\ rruga "7 Marsi", nr. 7693, Elbasan 3001, Albania \\ ${ }^{*, * \star E-m a i l ~ a d d r e s s: ~ a r d i a n s h i n g j e r g j i @ g m a i l . c o m ~, ~ b e s a s h i n g j e r g j i @ g m a i l . c o m ~}$
}

\begin{abstract}
Development is a multi-sided process entailing the changes occurring to the individuals in the course of their lifetime. In children, the development perceptions includes the interaction of such fields as the physical, emotional, cognitive and social domains. In this context, the interest fields of this study are those of the pre-school children's motor and linguistic skills as well as their games as necessary means effecting the development of these skills. Object of the study is the assessment of the level of motor and linguistic skills to 5-6 age-group children through playing. The study strives to answer to such questions as: on what motor and linguistic features and characteristics are those games perceived of? What are the effects of motor developments into the linguistic and cognitive development? To what ways the selected and applied models of those games make the skills assessment in these fields possible? To what aspects, the applied games models measure or assess certain indicators of the motor and linguistic skills in this age-group children? The research has been based on the concrete understanding of these age group children's features as well as on the modeling the games to be applied with these children in our pre-school institutions. Moreover, the results deriving from the application of those models have been transferred to the teachers and educators in the respective pre-school institutions of Elbasan Country.
\end{abstract}

Keywords: modeling; interaction; motor skills; linguistic skills; games

\section{INTRODUCTION}

Child development has been defined as a process of constant changes during which the child begins to exert ever more complicated levels of movements, thinking, communication and interaction with surrounding environment. The child development concept has been considerably evolving recently and is regarded to as a social actor and a potential contributor in the society. A child should not be considered as someone that will become a human being in the future but as someone presently existing as a human being. (James, A. \& Prout, A. 1997). The child development is much more than simply the physical growth and health. It also includes his/her mental, socio-cultural and spiritual development and is related with the realization of the child's inner potentials as an individual.

Some of the fundamental principles leading development as a whole are the principles of comprehensiveness and the interdependence which mean that the child development has 
simultaneously been affected by and affects all the ones it is associated with. (Evans, J.L. \& Myers, R.G. \& Ilfeld, E.M. 2000).

In the modern points of view, the nature and cultivation have been seen in an interdependent way. The development potentials have been written in the genes of every human being, but its actualization is dependent on the surrounding environment and the social interaction. To this regard, the contemporary studies have testified that environment effects by since the infancy, not only to the brain cells but even to the ways they connect to each-other. This is the reason why many specialists think that there is a critical period for learning which should be paid attention to, by supporting or inducing its development in the proper time and manner. Determining and understanding the pre-school children's education and actualization process in the main development fields such as: physical, emotional, cognitive, and social development is also very important.

\section{FEATURES OF THE PRE-SCHOOL CHILDREN'S MOTORIC AND LINGUISTIC DEVELOPMENT}

The various children's age groups anticipate a harmonic and conditioned development of their skills and wants in the respective fields, basing on the peculiar features they display. In these terms, our study is focused in the assessment of the 5-6 age-group children's motoric and linguistic skills through playing. In order to have an ever wider viewpoint of this intention of ours and to make the assessment of this age group children development possible we are presenting some of their peculiar features in the following:

\section{A- Physical and motor development.}

The pre-school children physical and motor development includes, in its entirety, their physical and locomotive features. The 3-6 age-group children develop more slowly then the first years of their life, but they have an ever growing progress into their muscles and mental development, especially when they are 5-6 years old.

Children of this age get $4.5-7 \mathrm{~cm}$ taller and gain $2-3 \mathrm{~kg}$ a year. They no more appear to be chubby and develop the belly muscles alongside the formation and the strengthening of the body lines. Boys have more muscles whereas girls more fat tissues. The growing limbs and lessening of the fatty tissues under the skin alongside getting more strength are development processes working in favor of the motor skills and capabilities (Grimm, 1966).

The tracking of the bigger motor skills development progress, including walking, jogging, jumping, the equilibrium, somersaulting and passing the ball, as well as the smaller motoric skills in sport accessories (the fine ones), including drawing, coloring, copying different figures, scissoring, etc, is also very important. Among the main factors of the progress linked with the intellectual development of the children of this age group, are the following:

- A considerable augmentation of socialization among children as well as the evanesce of their social status differences

- The gradual approaching to their school age (Kossakowski. Otto, 1971).

\section{$B$ - Linguistic development.}

Language is an important element of communication so that its acquisition is vital to every individual in the society. However, there is communication out of the linguistic one, too, (non-verbal communication, via symbols, gestures or mime). Despite their cultural descent, children come to life prepared to communicate via sounds, gestures and words. The facial 
expressions and bodily communications, (the ways the just born infants communicate), is later on replaced with "babbling", word formation and later on with words and sentences.

Children need the language to express their opinions and feelings, as well as to understand the other individuals they communicate everyday with. Some of the fundamental skills of the preschool children, regarding linguistic development, include their ability to understand spoken language, to acquire the vocabulary, to use various grammatical forms, to improve communicative abilities, the interest in reading books, abilities to express themselves in writing, etc.

The fast rate of the 5-6 years old children's linguistic and motor development, affects the learning process directly, determining, above all, their motor behaviors. In general, the 3 years old children have too limited autonomous and correct reaction capabilities to verbal responses, (oral responses). For example, they can respond correctly to only some simple verbal incitements, such as: "catch me", "take the ball", and "sit down", etc. The more detailed verbal directions or instructions are understood only if they are clearly linked with the respective demonstrations (practical presentments), of the moves and solely when the learner participates in the exercise. On the contrary, the 5-6 years old children, the development of the linguistic skills, is reflected, over all, in their childish vocabulary, which, compared to the forerunning ages is tenfold greater, amounting to 3000 words. (Novogrodoski, 1969). Consequently, if the motor exercise or game is clearly formed, without ambiguities and relevant to their understanding skills, only then will the children be able to react conform directions and with proper moves.

\section{1. Role of the games into the cognitive and linguistic development of the pre-school children.}

Playing is one of the fundamental children activities linked directly with their instinctive life. In other terms, playing has been determined as a preparatory exercise for the adult life and a constant and punctual verification of the gained experiences, by means of which they realize the equilibrium in the surrounding ambiance. Having the imagination as its simulative function, which is one of the mental development indicators, it acts freely in the perceptible reality, adapting the latter to the children's needs (Gray, J.K. 1998).

By creating a rich-in-games ambiance and supporting the children's attempts to "investigate" the world, we create premises to promote their cognitive development. This development is reflected in the changes occurring in the children's mental activities in general, as well as in other elements suchlike their memory, reasoning, perceptions, logics, etc. The cognitive abilities are gained in the course of interactions between each-other and the surrounding ambiance. Children of this age-group advance in terms of observations, interactions and the information processing and preservation. Every game, however simple it is, promotes participation and the children's intensive motor commitment, which helps children to integrate their psychomotor skills and gain new knowledge. As such, it favors not only their physical development but also the linguistic, social and spiritual one. (Tahsini, I. \& Ndrio, M. $\&$ Balli, D. 2012). Usage of the non-formal daily activities and games have been considered as possibilities to develop the children's vocabulary capabilities, to improve their daily language, their skills to tell stories or to describe various events, their thinking, fantasy and imagination. Taking all these aspects into consideration, regarding the role and the importance of applying games to promote different fields of child's development, the intention of this study has been the assessment of the level of the motor and linguistic skills through playing. 


\section{2. The application procedure}

The study was accomplished in the course of the observation and pedagogical practice classes of the students of the pre-school department of the Faculty of Education Sciences, at the EU “A. Xhuvani”, academic year 2011-12. Participating in the study were 302 children (56 years old) from 12 pre-school institutions of Elbasan Country. The selected Kindergartens were the following:

- In Elbasan town, pilot kindergarten No. 5, kindergarten No. 12 and kindergarten No. 4.

- The Kuqan, Katundi i Ri and Shushice village kindergartens, located at their respective 9-year schools

- Kindergarten No. 1, kindergarten No. 2 in Librazhd town: kindergarten No. 1 and kindergarten No. 2 in Gramsh town, kindergarten No. 1 and kindergarten No. 2 in Prrenjas town, the Prrenjas kindergarten, and the 9-year school "Halit Uruci" kindergarten, at Belesh Municipality.

The study was also supported by the interest groups such as the work group made up of the study authors, and the pilot kindergarten director, Ms Lira Ballhysa and the supportive group made up of the pre-school teachers of the involved kindergartens as well as the students of the pre-school department, at the Faculty of Education Sciences of the EU "Aleksander. Xhuvani"

In the course of the study investigation and observation practices to these institutions we got hold of the skills observation and the assessment model according to respective age groups, in different development fields. One of such models is the observation notebook, (Zisi, A. \& Selmani, L. \& Hamzaraj, S. 2009), wherein we are based, too, in drafting their motor and linguistic indicators observation and assessment formats.

However, specific for this study is that by means of the models of some selected and applied games, we realized the measurements of certain motor and linguistic indicators in 5-6 years old age-group children. (Kamani, P. \& Mato, E. 2004). To select these games we based on certain criteria such as: the age, easiness in learning and applying, as well as the efficiency of the followed method regarding the measurement of the motor and linguistic indicators by the pre-school teachers. Some of the measured motoric skills indicators are: coordination and speed of movement in the course of running, equilibrium, (both static and dynamic), jumping, (distance and height) ball throwing and catching as well as the fine skills such as drawing, coloring, scissoring, forming figures and constructions.

Regarding the linguistic skills we measured indicators that are connected with the application of speaking, writing, reading, listening and vision strategies. In order to properly apply these strategies the children need to mobilize the five main senses, all effecting directly in the improvement of communication.

\section{3. Methodical description of the games}

In the following we have presented a set of the selected games we have been based on to assess the level of the motor and linguistic skills in 5-6 years old children.

1. The locomotive game for assessing the motion coordination while running on straight line and by avoiding hurdles.

Method: Full running distance 10-15 m with four pyramids (cones) in the middle of the distance, $70-80 \mathrm{~cm}$ from each-other. Children are divided in two squads set in a file and are encouraged to run straightly and in winding course, (at the pyramids), as well as to return to the start line. The game is repeated until all the participants in the squad have finished and it can also be done as a race exercise. 


\section{The locomotive game for assessing the dynamic and static equilibrium skills.}

Method: Children, while uplifting their arms, are encouraged to walk on a 6-8m long and $5 \mathrm{~cm}$ wide white straight line, marked on the floor (or on the gymnastic stool), and then they run and stop abruptly within a circle, marked in a $4-5 \mathrm{~cm}$ distance from the line or the gymnastic stool. Later on they turn their faces to the start and stay on one leg for $10 \mathrm{secs}$, with their bodies and arms laid before them and the other leg lifted from behind. The game ends by running back to the start line.

\section{The locomotive game for assessing jumping skills.}

Method: Drawing 6 circles or putting real rings on the floor in an irregular alignment (zigzag), and number them. Children are encouraged to jump on both legs from one ring to the other, according to the ascending numbers. Later on the game advances by changing the rings and their numbering and by jumping on one or the other leg.

4. The game for assessing the ball anticipating skills such as catching, (catching, anticipation) and passing.

Method: Children are divided in two squads or groups located in files facing each-other, and are encouraged to pass and catch the ball. It begins with the passing of the ball from the first of the file to the first of the other file and once they have passed the ball they run at the end of the file: the game goes on like that until all have done the exercise. Later on the game may advance by running at the end of the other file, or lining the groups in to lines facing each other and passing and catching the ball in zigzag.

5. The combined game for assessing certain skills (suchlike running, jumping, orientation in time and space, locomotive coordination, hand-eye coordination etc).

Method: Children are divided in two squads, placed in columns at the front of the start line, and are encouraged to run by avoiding three vertical pyramids with a distance of $70-80 \mathrm{~cm}$ from each-other. Then they do two somersaults on the gymnastic mattress, to continue by jumping two horizontal $10-20 \mathrm{~cm}$ hurdles on both legs while trying to precisely throw the small ring (25$30 \mathrm{~cm}$ ), on the cone which is placed $1.2-1.5 \mathrm{~m}$ distance from the second jumping hurdle. The game ends when all the squad members have accomplished these elements and turn back to the start line. Squads are motivated by granting points to them, both for the time and the accomplishment technique and the precision of inserting the rings into respective cones.

\section{The game for assessing the fine motor skills.}

Method: Children are divided in 5-6 groups (3-4 persons each), in work tables and are encouraged to build constructions, figures with puzzles (18-20), as well as to draw, color, or form various figures they see and desire with plasticine.

7. The game for assessing the linguistic skills, enrichment of the vocabulary, and building the sentence patterns, through storytelling.

Method: Children sit down in a circle and the teacher begins to tell a story. She starts her story with the main character and its location describing in a few words what is going to happen and then passes the ball to the first child close to her asking him/her to add some more words related to the story, so asking to contribute. Later on the child passes the ball to the other student and so on. It is most likely that the story becomes meaningless; still, this is an efficient way to help pre-school children to develop their linguistic skills. 
8. The game to promote awareness about the sentence patterns, use of clauses via the usage of silly sentences.

Method: By means of this game children are taught the sentence patterns, since in their very young age they don't know to read. The teacher draws figures of nouns, adjectives, and uses them to construct a silly sentence for example: "The pink frog ate a pizza". Possibilities to create such sentences are infinite and it is sure that children are entertained and learn at the same time.

9. The game to develop speaking, hearing, visioning and logical operations: "Book detective".

Method: The teacher reads them a short story, illustrated and simple and invites (directs) them to play the role of the "detective" so that they are very attentive and understand its content, to distinguish the characters and the venue of the event. Once the teacher ends the story, she asks the children questions such as: Where does the event takes place? Who is the main character? What was he doing? How did he solve the problem?

\section{Rhyming games: aiming to understand different ways of speaking.}

Method: The teacher uses a suitable set of cards and figures or creates his/her own card index. By distributing the cards on the reverse side, hiding the figures, $\mathrm{s}$ /he plays the game of the memory combination. Later on $\mathrm{s} / \mathrm{he}$ directs the children to draw and at the same time to revert two cards with reversed figures, so that they create a couple of rhyming combinations. The game goes on that way until there are no more cards on the table.

11. The symbolic games, or the mimic games aiming to promote communication, transmission of the messages by miming and body movements.

Method: these games have been applied by relying on the following ideas:

- During the first teaching situation is communicated by imitating with hands to transmit meanings of the figurative illustrations, (one child imitates before the group or in couple facing each-other).

- In the second teaching situation the body is used with all its parts, with gestures to understand the message and by responding them with an opposite meaning, e.g. big/small, fat/slim, angry/happy, etc.

The assessment results of some of the motor and linguistic indicators for the 5-6 agegroup children, based on the skills observation and assessment format according to the specific development fields are reflected in the following presentation:

County: Elbasan

Number of kindergartens involved in the study: 12

Number of children: 302

Age group: 5-6 years old.

Table 1. The summary table with results from the skills observations and assessment for some of the Elbasan county kindergartens.

\begin{tabular}{|c|c|c|c|}
\hline \multirow{2}{*}{ Development Fields } & \multicolumn{2}{|c|}{ Observed behaviors } & \multirow{2}{*}{$\begin{array}{c}\text { Assessment in percentage } \\
\text { (\%) }\end{array}$} \\
\cline { 3 - 4 } Motor Skills & \multirow{2}{*}{ Yes } & No & \\
\hline $\begin{array}{c}\text { 1. Combines legs and arms } \\
\text { movements while running. }\end{array}$ & 208 & 94 & $69 \%$ \\
\hline
\end{tabular}




\begin{tabular}{|c|c|c|c|}
\hline $\begin{array}{c}\text { 2. Walks on the gymnastic } \\
\text { bench or on a } 3-5 \mathrm{~cm} \text { wide and } \\
6-8 \mathrm{~m} \text { long line. }\end{array}$ & 245 & 57 & $81 \%$ \\
\hline $\begin{array}{l}\text { 3. Stands on one leg for } 10 \\
\text { seconds. }\end{array}$ & 251 & 41 & $83 \%$ \\
\hline $\begin{array}{l}\text { 4. Jumps over } 10-20 \mathrm{~cm} \\
\text { hurdles. }\end{array}$ & 227 & 75 & $75 \%$ \\
\hline $\begin{array}{l}\text { 5. Passes and catches the ball, } \\
\text { follows the trajectory. }\end{array}$ & 202 & 100 & $67 \%$ \\
\hline $\begin{array}{l}\text { 6. Makes 5-6 somersaults both } \\
\text { backwards and forwards. }\end{array}$ & 157 & 145 & $52 \%$ \\
\hline $\begin{array}{l}\text { 7. Makes controlled motor } \\
\text { actions in continuity, runs, } \\
\text { jumps, rolls, throws objects } \\
\text { accurately. }\end{array}$ & 193 & 109 & $64 \%$ \\
\hline 8. Unites $18-20$ puzzles. & 175 & 127 & $58 \%$ \\
\hline $\begin{array}{l}\text { 9. Draws figures, colors within } \\
\text { the line, scissors and forms } \\
\text { structures. }\end{array}$ & 257 & 45 & $85 \%$ \\
\hline \multicolumn{4}{|l|}{$\begin{array}{c}\text { Linguistic and communication } \\
\text { skills. }\end{array}$} \\
\hline $\begin{array}{l}\text { 1. Tells a full event as it has } \\
\text { occurred. }\end{array}$ & 211 & 91 & $70 \%$ \\
\hline $\begin{array}{l}\text { 2. Distinguishes the story } \\
\text { characters. }\end{array}$ & 278 & 24 & $92 \%$ \\
\hline $\begin{array}{l}\text { 3. Memorizes the venue of the } \\
\text { event. }\end{array}$ & 281 & 21 & $93 \%$ \\
\hline $\begin{array}{l}\text { 4. Finds reasons about the } \\
\text { characters behaviors and } \\
\text { actions. }\end{array}$ & 242 & 60 & $80 \%$ \\
\hline $\begin{array}{l}\text { 5. Imitates by figures } \\
\text { (Indirectly). }\end{array}$ & 260 & 42 & $86 \%$ \\
\hline $\begin{array}{l}\text { 6. Imitates through actions } \\
\text { (directly). }\end{array}$ & 217 & 85 & $72 \%$ \\
\hline $\begin{array}{l}\text { 7. Makes simple clauses and } \\
\text { sentences through linguistic } \\
\text { games and silly sentences. }\end{array}$ & $\begin{array}{l}284 \\
227\end{array}$ & $\begin{array}{l}18 \\
75\end{array}$ & $\begin{array}{l}94 \% \\
75 \%\end{array}$ \\
\hline $\begin{array}{l}\text { 8. Creates rhymes via linguistic } \\
\text { games. }\end{array}$ & 230 & 72 & $76 \%$ \\
\hline $\begin{array}{l}\text { 9. Identifies his/her name as } \\
\text { well as his/her town (village) } \\
\text { name when asked. }\end{array}$ & 290 & 12 & $96 \%$ \\
\hline
\end{tabular}

\section{RESULTS AND DISCOURSES}

Since the aim of the study is not limited to the statistical data but in the origin of the effects it shapes, one can naturally ask the question: What are the respective conclusions and how to interpret them?

The study results in the field of motoric development show the following: 
1. The development level of the walking and running skills, especially the coordination of the upper and lower limbs' movements, is $69 \%$ or lower as compared to the indicators from contemporary bibliography, in which the percentage of the well-coordinated movements in 56-years old children sways to 70-90\%. (Levi-Gorinewskaia, 1955). Pilot kindergarten no. 5 makes up an exception for this indicator, (78\%), wherein, a comparison with other kindergartens involved in the study shows that it has higher levels. In terms of gender (boys/girls) differences are insignificant.

2. The development level of the equilibrium skills results to be satisfactory. The figures $83 \%$ for the ability of the static equilibrium and $81 \%$ for the ability of the dynamic equilibrium are very significant, showing that children of this age group manage to perform the curricula elements correctly. It is worth mentioning that regarding the static equilibrium the girls show better abilities as compared with boys which are conform to the studies from foreign scholars. (Sigmundson \& Rostoft, 2003). On the other hand, regarding the dynamic equilibrium, there are essential variations between the two genders, which show that these skills are developed in the course of the age.

3. Regarding the level of the jumping skills development, both the long and the high jumping and jumping hurdles, in terms of global accomplishments of those elements, result in relatively satisfactory figures (about $75 \%$ ). This is linked with the fact that different forms of jumping movements, (on both legs, on one or the other leg, jumping rings simultaneously or zigzag, numbered rings etc), have been augmented significantly, as well as the satisfaction these motor elements arise, always being in obvious progress for this age group as compared to the previous one. (Lewin, K. 1967). Considered in the specialistic point of view, the accomplishment of these elements is characterized by many deficiencies such as the irregular placement of the feet in regard with the position of the lower limbs, the knee articulations, the incorrect position of the trunk which brings the disruption of the equilibrium in the course of jumping, lack of coordination between the arms and the position of crawled legs during jumping, etc. All these observed and assessed deficiencies, according to our judgment, are a consequence of the lower scale the children involvement, lack of the proper means promoting the games activities, lack of stimulations, instances, and models to be followed.

4. The level of the anticipation abilities indicator (ball catching and passing) results under the average level, $67 \%$. This not satisfactory indicatory level has been reflected during the locomotive games observation and assessment sessions with the children of this age group, displaying typical deficiencies such as: the non-correct position of the legs, trunk, arms which are not position straightly to the ball, the hand palms are distant from each-other, they do not correspond to its diameter and the fingers are not easily open. In addition to this, this development level is even lower when referring to the combined movements linked with the quick and dexterous movements for catching and passing the ball, anticipation of the ball trajectory, wherein only $6 \%$ of the children manage to achieve. According to the foreign authors studies, (Dobler, 1961, Lewin, K. 1961, 1963, 1965, 1971), about $10 \%$ of this agegroup children manage to accomplish such movements which require the evolvement of a variety in forms of accomplishments.

5. In determining the development level of the motoric control skills, we focused in some forms of movements, such as combination of vertical hurdles running with forward and backward somersaulting, jumping over vertical hurdles, and throwing objects accurately, the (sensory coordination eye-hand). The figure $64 \%$ reflects a not-good level of the development for these coordinative abilities, in which the elements indicating more difficulties to be realized by children are the forward and backward somersaults, (only $52 \%$ of children manage to achieve 
them). These figures show that the development of those abilities in children of this age group cannot be left to spontaneity, but they require qualified and led interventions, so that the possibilities to control their movements are made more effective.

6. In regard to the development level of the fine motor abilities, figures reflect a satisfactory level, about $85 \%$ which means that games with constructions, drawing figures, coloring within contours, scissoring, or working with plasticine are likable activities for children and are directed with full commitment by the pre-school teachers. It is worth to be mentioned that games with puzzles to form figures, (matching 18-20 puzzles), seem to be too difficult for children to realize this element of the curricula: figures show that $58 \%$ of them manage to accomplish this task. We think that the main reason is the fatigue and the boredom, because of the lack of concentration in a relatively longer time compared to other fine motor activities. In the field of the linguistic formation, which means promoting and aiding the group language learning, as a need to communicate with others, the results obtained brought us to the following results:

a. About $96 \%$ of the children can identify their name, the name of their town, (village), and their country's when asked. This is a satisfactory result in determining the identification data.

b. About $79 \%$ of the children involved in the games to develop linguistic abilities, enrichment of the vocabulary and building the sentence patterns by storytelling, mange to complete the full story. This is a relatively good indicator. In the course of application of this game the children's desire to participate in the continuation of the narration was motivated by introducing new characters, placing them into new ambiances and by telling events created by them. The narration did not ensure logical continuation, however, by means of it children created clauses and sentences and qualifiers were used to characterize the ambiance characters. The verb moods were correctly used in different tenses suchlike the perfect, the simple perfect, the imperfect, although the use of these verb tenses was spontaneous and self-conscious.

c. In the games aiming to promote the development of speaking, listening, visioning, and logical operations, the book Detective, about $92 \%$ of the children can distinct the characters in a story, which is a satisfactory level of achievement. Also, $93 \%$ of them can remember the events venue and can name it, whereas $80 \%$ of them find the reasons why the characters' behaviors and actions happen, a good indicator which is closely linked with the logical operations to discover the cause-effect links of the actions performed by characters.

d. The application of the rhyming games, aiming to get aware of the children's ways of speaking, $76 \%$ of them can find words that rhyme, a rhyme notion which is very perceptive for them. This has been shown with the relatively good indicator.

e. About $94 \%$ of the children involved in the games aiming to promote awareness about the sentence patterns by means of silly sentences can create clauses while respecting the order of the patterns, a satisfactory indicator regarding the achieved level. This indicator is relatively good for creating sentences in which $75 \%$ of the children can create sentences, mainly conjunctive sentences. Although the game was well-received by children, since it placed them in silly situations, the linguistic indicators showed that there is still need to be improved.

f. In symbolic games or, differently, the mimic games, which intend to explore the level of communication, message transmission by means of gestures and body movements, the children were placed in situations with different scales of difficulty, so that the levels achieved by the children of this age group are variable. In the first situation the direct imitation was proposed to children, (Imitation is made by the object drawings). About $86 \%$ of the children can 
communicate by means of hands and body. In the second situation, in a higher scale of difficulty, the direct imitation is proposed: (imitation of actions). About $72 \%$ of the children communicate in group by understanding the message and by responding it to the opposite imitation, for example big/small, fat/thin, angry/happy, etc. The second indicator shows that the symbolic games should be applied widely in the teaching process to bring variety in communication.

\section{CONCLUSIONS}

A. In our study we strived to bring a functional and simple model for the assessment of the preschool children's motor and linguistic skills (age-group 5-6 years old), through playing. Since games cover a considerable part of the curricular activities in different fields of their development, we offer this model which might be used by the pre-school students and teachers in their work with the children.

B. The selected games models used by us were well-received an actualized in a satisfactory way, not only by the group of the pre-school students and teachers but even by the children themselves, which reinforces our opinion that these games can be applied widely, serving as an assessment model for their achievement in these two fields of development.

C. The obtained results in the motor ambit, showed a non-satisfactory development level of these skills, especially in such indicators as locomotive coordination in running, the motor check up skills, the anticipation skills as well as in some of the fine motor indicators, linked with formation of the figures with puzzles. We think and judge that the main causes should be found at non-involvement of children into activities and games which promote the development of those skills by the pre-school teachers, due to their insufficient awareness and practical directions in the psychomotor education, lack of their training and continuous qualifications from the field specialists as well as the lack of infrastructure and other necessary didactical means to develop these skills in the instructive and teaching processes.

D. However, in the field of linguistic development, the results showed a good level compared to the indicators of motor development. We think that the reason lying behind this is the fast progress of this age-group children's intellectual and linguistic capacity, which can be explained with the children being closer to the school age, as well as the awareness they have acquired thanks to the good work of the pre-school teachers to this regard. It is worth mentioning the fact that in this field, as well, there is place for improvements, especially in some indicators which are linked with the development of the linguistic skills, the formation of the sentence patterns, ways of speaking and the use of rhymes.

E. Being that these results reflect the development level for these skills, the necessity for the contribution of specialists, pre-school education directors and teachers, becomes ever pressing, to consider these problems for further improvement, in drafting effective curricula and directions for the development of these skills. 


\section{References}

[1] Evans J. L., Myers R. G., Ilfeld E. M., Early Childhood Counts: A Programming Guide on Early Childhood Care and Development. (2000). Washington DC, Worlds Bank. $18-22$.

[2] Gray J. K., The Philosophy of the children's development, games and sport activities. (1998). Manual published by AEDP. Tirana. 3-28.

[3] James A., Prout A., Constructing and Reconstructing Childhood. (1997).

[4] Kamani P., Mato E., Achieved standards in the pre-school education. (2004). ISP. Tiranë, 5, 18-19, 20, 37-38, 39, 61-62.

[5] Mato E., Kamani P., Sina E., Ndrio M., A world to be discovered .Practical directions for the pre-school education children. (2010). Save the Children. Tirana.17-24, 70-74, 100, 136-137.

[6] Meinel K., Schnabel G., Theory of Movement. (1984). Societa Stampa Sportiva. Roma 338-345.

[7] Sigmundson H., Rostoft M. S., Scandinavian Journal of Educational Research 47 (2003) 451-459.

[8] Tahsini I., Ndrio M., Balli D. Happy children make happy parents. You can make it. Directions to help you be a successful parent to a pre-school child. (2012). Save the Children. Tiranë, 8-20, 27, 63-73.

[9] Zisi A., Selmani L., Hamzaraj S., Observe and assess. About the 5-6 years children. (2009). Tirana.6-7, 10-11, 16-17. 